\title{
MORFOLOGI DAN PRODUKSI BIOMASSA Chloris gayana cv. Callide, DAN Megathyrsus maximus cv. Gatton PADA TAHUN PERTAMA PENANAMAN DI YOGYAKARTA
}

\author{
Nafiatul Umami dan Nilo Suseno \\ Fakultas Peternakan Universitas Gadjah Mada, Yogyakarta \\ e-mail : nafiatul.umami@ugm.ac.id
}

\begin{abstract}
ABSTRAK
Penelitian ini bertujuan mengetahui karakter morfologi dan produksi biomasa Chloris gayana cv. Callide dan Megathyrsus maximus cv. Gatton yang diintroduksi di Yogyakarta pada tahun pertama penanaman. Tanaman tersebut ditanam dengan menggunakan biji dalam plot ukuran 2x2 m dengan cara menebar biji dan masing-masing spesies ditanam dengan 5 replikasi. Data yang diamati meliputi karakter morfologi, produksi biomasa, kadar bahan kering dan bahan organik. Data yang diperoleh dianalisis secara deskripsi dan dengan metode t-test. Rumput yang diintroduksi merupakan tanaman perennial. Pertumbuhan tanaman menunjukkan pertumbuhan yang baik. Morfologi tanaman normal sesuai karakter kedua tanaman ini. Chloris gayana cv. Callide memiliki produksi hijauan kering 25,21 ton/ha/ tahun pada tahun pertama (kadar BK 19,70\% dan kadar BO 88,20\%). Megathyrsus maximus cv. Gatton memiliki produksi hijauan kering 32,44 ton/ha/tahun pada regrowth kedua (kadar BK 19,85\% dan kadar BO 88,18\%). Berdasarkan penelitian dapat disimpulkan bahwa Megathyrsus maximus cv. Gatton memiliki produksi biomassa lebih tinggi dari Chloris gayana cv. Callide.
\end{abstract}

Kata kunci: Chloris gayana, Megathyrsus maximus, morfologi, perennial, produksi biomassa, regrowth

\section{MORPHOLOGY AND BIOMASS PRODUCTION OF Chloris gayana cv. Callide, AND Megathyrsus maximus cv. Gatton IN THE FIRST YEAR OF PLANTING IN YOGYAKARTA}

\begin{abstract}
This study aimed to determine the morphological character and biomass production of Chloris gayana cv. Callide and Megathyrsus maximus cv. Gatton was introduced in Yogyakarta in the first year of planting. The plants were grown using seeds in plots measuring $2 \times 2 \mathrm{~m}$ by spreading the seeds. Each species was planted with 5 replications. The data observed included morphological characters, biomass production, dry matter, and organic matter content. The data obtained were analyzed by descriptive and by t-test method. The introduced grass was a perennial plant that showed good growth. Plant morphology was normal according to the characters of these two plants. Chloris gayana cv. Callide had a dry matter production of 25.21 ton/ha/year in the first year (19.70\% DM and 88.20\% OM). Megathyrsus maximus cv. Gatton has a dry matter production of 32.44 ton/ha/year in the second regrowth (19.85\% DM and 88.18\% OM). Based on the research, it was concluded that Megathyrsus maximus cv. Gatton has higher biomass production than Chloris gayana cv. Callide.
\end{abstract}

Key words: Chloris gayana, Megathyrsus maximus, morphology, perennial, biomass production, regrowth.

\section{PENDAHULUAN}

Ketersediaan hijauan pakan yang unggul selalu menjadi persoalan yang perlu diselesaikan dalam pengembangan hijauan pakan. Oleh karena itu, dibutuhkan varietas hijauan pakan baru yang memiliki kualitas dan produksi yang baik agar dapat mencukupi kebutuhan pakan dari segi kualitas dan kuantitas serta kontinyuitas di Indonesia. Pengem- bangan hijauan dapat dilakukan dengan introduksi hijauan pakan yang berkualitas. Biasanya tanaman introduksi memiliki produktivitas yang sangat tinggi sehingga tanaman ini disebut juga dengan tanaman unggul (Prawiradiputra et al., 2006). Rumput pakan yang diintroduksikan adalah rumput yang belum ada di suatu wilayah antara Chloris gayana cv. Callide dan dibandingkan dengan tanaman Megathyrsus maximus cv. Gatton. Rumput Chloris gayana cv. 
Callide ini tahan kekeringan, sangat produktif, dan berkualitas tinggi (Cook et al., 2005).

Beberapa penelitian melaporkan bahwa di Sumatera Utara selama setahun dapat menghasilkan 38 ton/ha/ tahun (Skerman dan Riveros, 1990). Produksi bahan kering antara 30-40 ton/ha (Murphy, 2010), Rusdiana dan Herdiawan (2017), menyatakan dengan hasil bobot segar diperoleh 160,83 g/rumpun. Rumput Megathyrsus maximus cv. Gatton memiliki tipe pertumbuhan yang cepat dibandingkan dengan tipe pendek, produksinya lebih tinggi serta memiliki palatabilitas tinggi. Sajimin (2005) melaporkan bahwa Meganthyrsus maximus memiliki beberapa kultivar yaitu (1) tipe besar dengan tinggi antara 3,6 sampai 4,2 m seperti cv. Hamil, (2) tipe sedang dengan tinggi antara 1,5 sampai 2,5 m seperti cv. Common dan cv. Gatton, (3) tipe pendek dengan tinggi sampai 1,0 m antara lain cv. Sabi dan cv. Trichoglume (Sajimin, 2005). Produksi biomass dalam kondisi segar menurut Sajimin (2005) sebesar 1111,80 g/ $\mathrm{m}^{2}$ dan 189,00 $\mathrm{g} / \mathrm{m}^{2}$ kering atau 1,89 ton/ha. Kelebihan lain adalah toleran pada kondisi $\mathrm{pH}$ asam bila ditanam dengan pengairan baik. Dapat digunakan dalam jangka panjang atau perenian dan tanaman ini memiliki total produksi bahan kering 30 ton/ha/tahun (Cook et al., 2005). Tanaman ini mampu beradaptasi pada berbagai jenis tanah antara lain tanah latosol (Sajimin, 2005), tanah lempung berpasir (Taute et al., 2002), tanah liat berpasir dan liat (Corleto et al., 2009).

Produksi hijauan pakan dalam usaha peternakan bergantung pada kekuatan dan persistensi rumput perennial, dan dipengaruhi salah satunya faktor manajemen penanaman, pemeliharaan, dan pemanenan. Kondisi lingkungan juga akan mempengaruhi hasil yang didapatkan, sehingga pada penelitian ini mempelajari bagaimana karakteristik morfologi, produksi biomassa, dan produksi bahan organiknya saat penanaman tahun pertama di Yogyakarta dari spesies Chloris gayana cv. Callide dan Megatyrsus maximus cv. Gatton.

\section{MATERI DAN METODE}

Penelitian dilakukan di Kebun Penelitian Hijauan Makanan Ternak dan Pastura Fakultas Peternakan UGM dengan menggunakan benih berupa biji tanaman Chloris gayana cv Callide dan Megathyrsus maximus cv Gatton yang berasal dari Crop Mark Seed Company New Zealand. Persiapan lahan dilakukan dengan membuat plot penanaman dengan ukuran $2 \times 2 \mathrm{~m}$ sebanyak 5 replikasi untuk satu jenis tanaman. Kandungan hara tanah dianalisis untuk mengetahui kadar $\mathrm{C}, \mathrm{N}, \mathrm{P}, \mathrm{K}, \mathrm{pH}$, dan $\mathrm{C} / \mathrm{N}$ seperti yang tersaji pada Tabel 1. Pengambilan data klimatologi meliputi temperatur, curah hujan, dan kelembaban diambil menggunakan data online Badan Meterologi, Klimatologi dan Geofisika (BMKG) Sleman Yogyakarta tahun 2019. Penanaman dilakukan dengan menebar biji dengan jumlah 3 gram $/ \mathrm{m}^{2}$ sehingga masing-masing spesies ditimbang sebanyak $12 \mathrm{~g}$ per petakan. Pemeliharaan tanaman dilakukan dengan penyiraman dan penyiangan. Pemupukan dilakukan pada hari ke-15 setelah penanaman pertama pupuk yang digunakan adalah pupuk NPK sebanyak $2 \mathrm{~g} / \mathrm{m}^{2}$. Pemanenan dilakukan ketika tanaman sudah berumur 45 hari. Pengukuran morfologi dilakukan dengan mengukur tinggi dan panjang tanaman, panjang dan lebar daun, banyaknya tiller serta diameter batang. Tanaman yang sudah mencapai umur panen dipotong menggunakan sabit kurang lebih 10 sampai $15 \mathrm{~cm}$ dari permukaan tanah. Tanaman yang telah dipanen, ditimbang berat segarnya, lalu dimasukkan ke dalam kantong koran untuk dilakukan uji lanjutan di laboratorium untuk menentukan kadar BK dan BO pada tanaman.

Analisis Independents Sample T-test digunakan untuk membandingkan data morfologi dan produksi tiap-tiap spesies. T-test akan dilakukan dengan aplikasi SPSS for Windows 16.0 (Astuti, 2007).

\section{HASIL DAN PEMBAHASAN}

\section{Kondisi Tempat Penelitian}

Lokasi penelitian terletak di Karang Malang Yogyakarta dengan garis lintang $-7,769238$, garis bujur 110,386085 , dengan kemiringan lahan o sampai $2 \%$ pada ketinggian $165 \mathrm{~m}$ dpl. Jenis tanah yang digunakan adalah tanah regosol, dan memiliki komposisi kimia tanah yang dapat dilihat pada Tabel 1.

Tabel 1. Hasil analisis tanah kebun lokasi penelitian Chloris gayana cv. Callide dan Megathyrsus maximus cv. Gatton di Karangmalang

\begin{tabular}{lc}
\hline \multicolumn{1}{c}{ Parameter } & Hasil \\
\hline $\mathrm{pH}\left(\mathrm{H}_{2} \mathrm{O}\right)$ & 6,87 \\
C-organik (\%) & 5,46 \\
$\mathrm{~N}$ total (\%) & 0,57 \\
$\mathrm{P}_{2} \mathrm{O}_{5}(\mathrm{ppm})$ & 180,00 \\
$\mathrm{~K}(\mathrm{ppm})$ & 600,00 \\
$\mathrm{C} / \mathrm{N}$ & 9,58 \\
\hline
\end{tabular}

Tabel 1 menunjukkan bahwa derajat keasaman (pH) tanah yaitu 6,87, hal ini menunjukkan nilai $\mathrm{pH}$ netral. Menurut Syekhfani (2001), pH tanah netral berkisar antara 6,7 sampai 7,3. Keasaman atau $\mathrm{pH}$ tanah berpengaruh pada pertumbuhan tanaman pada hara tertentu yang dibutuhkan oleh tanaman untuk tumbuh dan pertumbuhan ulang. Cook et al. (2005) menyatakan bahwa pH optimum Chloris gayana yaitu sekitar 5,5 sampai 7,5 sedangkan Megathyrsus maximus cv. Gatton dinyatakan oleh Sajimin (2005) pada 
pH asam yaitu 4,6 mampu menghasilkan produksi bahan kering 1,8 ton/ha. Peneliti lain melaporkan bahwa pada $\mathrm{pH}$ 8, Megathyrsus maximus cv. Gatton memiliki produksi bahan kering sebanyak 2,71 ton/ ha (Corleto et al., 2009). Megathyrsus maximus cv. Gatton mampu berproduksi baik pada $\mathrm{pH}$ tanah yang asam hingga basa.

Berdasarkan hasil analisis tanah Tabel 1 juga menunjukkan bahwa fosfor dan kalium pada tanah dalam kondisi kurang sehingga perlakuan pemupukan NPK menjadi solusi untuk menambahkan unsur fosfor dan kalium, sehingga kebutuhan unsur hara makro dapat terpenuhi. Kadar karbon (C-organik) pada lahan penelitian yaitu 5,46\% dan kadar $\mathrm{N}$ yaitu 0,57\%. Kadar N dikatakan sedang apabila di dalam tanah berkisar antara 0,2 sampai 0,5\%, dan kadar $\mathrm{N}$

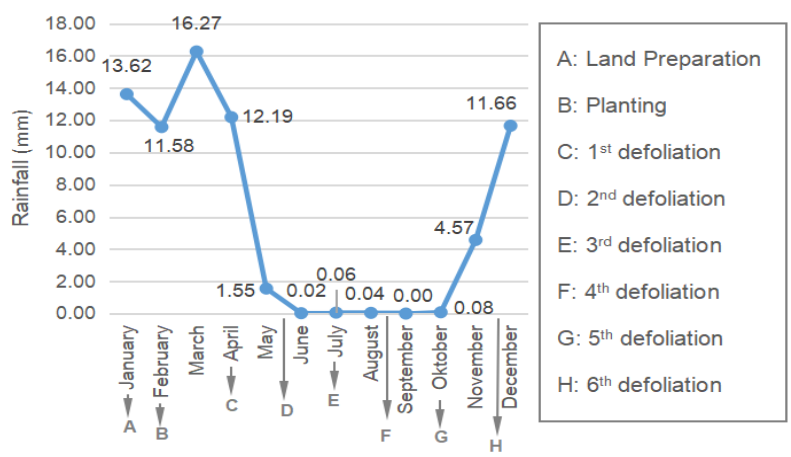

Gambar 1. Data curah hujan di Sleman Yogyakarta pada bulan Januari sampai Desember 2019 di lokasi penelitian

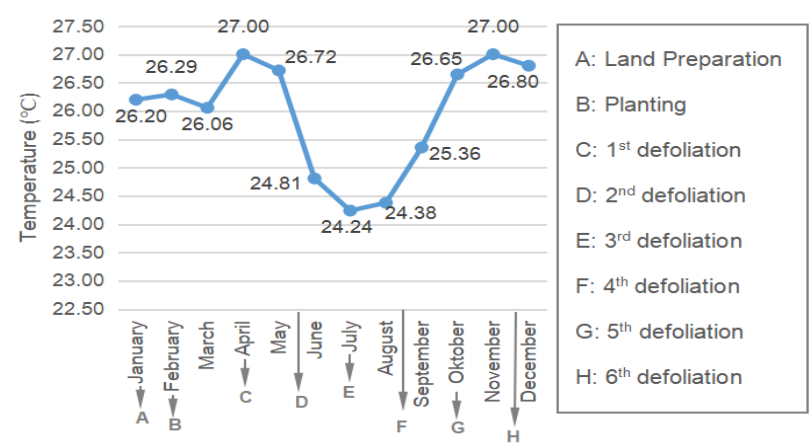

Gambar 2. Data suhu di Sleman Yogyakarta pada bulan Januari sampai Desember 2019 di lokasi penelitian

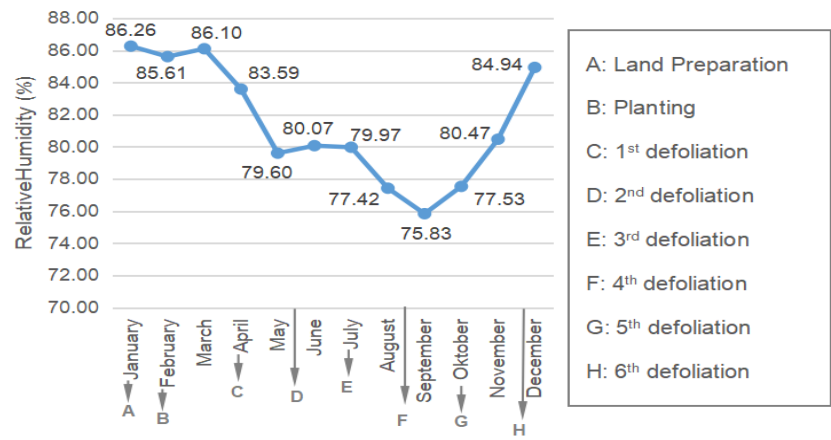

Gambar 3. Data kelembaban di Sleman Yogyakarta pada bulan Januari sampai Desember 2019 di lokasi penelitian dikatakan tinggi apabila berkisar antara 0,5 sampai 1,0\% (Landon ,1984).

Data klimatologi yang meliputi suhu, kelembaban, dan curah hujan tersaji pada Gambar 1, 2, dan 3 menunjukkan curah hujan, suhu, dan kelembaban di lokasi penelitian selama tahun 2019.

Selama satu tahun suhu berkisar 24,24 sampai $27^{\circ} \mathrm{C}$. Suhu optimal untuk habitat rumput adalah $31^{\circ} \mathrm{C}$, dengan suhu minimal antara 5 sampai $8^{\circ} \mathrm{C}$ dan suhu maksimal $50^{\circ} \mathrm{C}$. Lebih lanjut dinyatakan bahwa Chloris gayana cv. Callide tumbuh subur pada temperatur tahunan 16,5 sampai $26^{\circ} \mathrm{C}$ dan Megathyrsus maximus cv. Gatton tumbuh baik pada suhu 19,1 sampai $22,9^{\circ} \mathrm{C}$. Peneliti lain menyatakan bahwa, Megathyrsus maximus cv. Gatton tumbuh baik pada rentang suhu 18 sampai $32^{\circ} \mathrm{C}$ (Pieterse, 1999).

\section{Karakteristik Morfologi dan Produksi Chloris gayana cv. Callide dan Megathyrsus maximus cv Gatton}

Chloris gayana cv. Callide dan Megathyrsus maximus $c v$. Gatton adalah dua rumput yang berkembang di negara tropis maupun subtropik dan bersifat perenial. Kelebihan dari rumput ini antara lain dapat bertahan hidup di daerah kering, palatabilitas tinggi, toleran terhadap kadar garam tinggi dan toleran terhadap penggembalaan berat (Sutedi et al., 2004). Morfologi tanaman ini telah dilaporkan oleh Cook et al. (2005) bahwa rumput Chloris gayana memiliki daun yang halus tidak berbulu dan berwarna hijau terang kecoklatan dan menjadi kecoklatan saat semakin tua.

Megathyrsus maximus cv. Gatton merupakan salah satu kultivar dari rumput Megathyrsus maximus atau nama lainnya adalah rumput benggala (Panicum maximum). Tipe tumbuh Megathyrsus maximus cv. Gatton adalah tegak dengan warna daun hijau muda, tekstur berbulu halus dan batang hijau muda. Pertumbuhan secara vegetatif dimulai dengan perpanjangam batang dan pelebaran ukuran diameter batang. Sifat tanaman ini adalah perennial dan memiliki jumlah anakan yang bertambah seiring dengan pertambahan defoliasi tanaman.

Berdasarkan pengukuran selama pengamatan dalam penelitian, diperoleh data pertumbuhan Chloris gayana cv. Callide dan Megathyrsus maximus cv. Gatton tersaji dalam Tabel 2. Pengukuran dilakukan pada umur 60 hari setelah defoliasi pada regrowth keempat.

Tabel 2 menunjukkan data tinggi tanaman, panjang tanaman, panjang daun, lebar daun serta jumlah anakan pada kedua jenis tanaman ini memiliki perbedaan dengan tinggi tanaman, panjang tanaman, dan panjang daun lebih panjang Chloris gayana cv. Callide dibandingkan Megathyrsus maximus cv. 
Tabel 2. Data Tinggi, Panjang, Lebar Daun dan Panjang Daun Chloris gayana cv. Callide dan Megathyrsus maximus cv. Gatton pada Umur 6o Hari Setelah Tanam pada regrowth Keempat

\begin{tabular}{lcccc}
\hline \multicolumn{1}{c}{ Jenis Tanaman } & Tinggi tanaman $(\mathrm{cm})$ & $\begin{array}{c}\text { Panjang tanaman } \\
(\mathrm{cm})\end{array}$ & Panjang daun (cm) & Lebar daun (cm) \\
\hline Chloris & $150,60^{\mathrm{a}} \pm 2,25$ & $176,25^{\mathrm{a}} \pm 4,21$ & $50,78^{\mathrm{a}} \pm 2,65$ & $0,90^{\mathrm{b}} \pm 0,22$ \\
Megathyrsus & $100,83^{\mathrm{b}} \pm 3,41$ & $110,65^{\mathrm{b}} \pm 3,22$ & $39,14^{\mathrm{b}} \pm 2,44$ & $34^{\mathrm{a}} \pm 1,50$ \\
\hline
\end{tabular}

ab Superskrip yang berbeda pada baris yang sama, menunjukkan perbedaan signifikan $(\mathrm{P}<0,05)$

Gatton $(\mathrm{P}<0,05)$. Jumlah anakan juga lebih banyak Chloris gayana cv. Callide dibandingkan Megathyrsus $(\mathrm{P}<0,05)$ sedangkan lebar daun Megathyrsus maximus cv. Gatton lebih lebar dibanding Chloris gayana cv. Callide $(\mathrm{P}<0,05)$.

Penelitian yang dilakukan Cook et al. (2005) menyatakan bahwa tanaman Cloris gayana memiliki tinggi berkisar 1 sampai 2 meter, tanaman ini memiliki sifat tumbuh perenial dan tinggi tanaman antara 60 sampai $150 \mathrm{~cm}$. Begitu juga dengan parameter panjang daun, Cook et al. (2005), menyatakan bahwa panjang daun Chloris gayana yaitu sekitar 12 sampai $50 \mathrm{~cm}$ dan lebar daun sekitar 0,5 sampai $1 \mathrm{~cm}$.

Tinggi maksimal yang dicapai rata-rata 100,83 $\mathrm{cm}$ pada regrowth keempat umur 60 hari. Penelitian yang dilakukan oleh Corletto et al. (2009) di lingkungan subtropis Italia bagian selatan disebutkan rata-rata tinggi yang bisa dicapai Megathyrsus maximus $\mathrm{cv}$. Gatton yaitu $76 \mathrm{~cm}$ dari data yang diperoleh, tinggi Megathyrsus maximus cv. Gatton lebih tinggi di Yogyakarta.

Daun Megathyrsus maximus cv. Gatton memiliki bentuk memanjang seperti pedang dengan dua sisi simetris dan warna tulang daun hijau muda, dengan model midrib atau urat daun yang sejajar dengan tulang dain. Daun memiliki sedikit bulu halus di permukaan dan bagian tepi daun memiliki tekstur agak kasar. Hasil penelitian Fanindi dan Sutedi (2014) melaporkan bahwa daun Megathyrsus maximus cv. Gatton memiliki bulu dengan tekstur halus dengan bagian tepi yang bertekstur kasar. Produksi biomassa tanaman saat penelitian dapat dilihat pada Tabel 3.

Tabel 3. Produksi Biomassa Chloris gayana cv. Callide dan Megathyrsus maximus cv. Gatton pada Penanaman Satu Tahun Pertama

\begin{tabular}{l|c|c}
\hline \multicolumn{1}{c|}{ Parameter } & $\begin{array}{c}\text { Chloris gayana } \\
\text { cv. Callide }\end{array}$ & $\begin{array}{c}\text { Megathyrsus } \\
\text { maximus cv. } \\
\text { Gatton }\end{array}$ \\
\hline Produksi segar (ton/ha/tahun) & $110,40^{\mathrm{a}^{\mathrm{a}} \pm 3,05}$ & $121,02^{\mathrm{b}} \pm 2,23$ \\
Produksi BK (ton/ha/tahun) & $25,21^{\mathrm{a}} \pm 1,05$ & $32,44^{\mathrm{b}} \pm 0,14$ \\
Kadar BK\% & $19,7 \mathrm{O}^{\mathrm{a}} \pm 0,02$ & $19,85^{\mathrm{b}} \pm 0,06$ \\
Produksi BO (ton/ha/tahun) & $98,58^{\mathrm{a}} \pm 1,95$ & $106,92^{\mathrm{b}} \pm 1,20$ \\
Kadar BO \% & $88,20^{\mathrm{a}} \pm 0,17$ & $88,18^{\mathrm{a}} \pm 0,21$ \\
\hline
\end{tabular}

ab Superskrip yang berbeda pada baris yang sama, menunjukkan perbedaan signifikan $(\mathrm{P}<0,05)$
Produksi segar Chloris gayana cv. Callide pada tahun pertama penanaman adalah 110,40 ton/ha/ tahun dengan pemanenan selama 6 kali, umur potong awal adalah 60 hari dan selanjutnya 45 hari setelah defoliasi, semakin beriringnya regrowth kemampuan pertumbuhan tanaman semakin baik. Hasil ini lebih rendah dibandingkan Megathyrsus maximus cv. Gatton $(\mathrm{P}<0,05)$ yaitu 121,02 ton/ha/tahun. Kandungan bahan kering dan bahan organik Chloris gayana cv. Callide lebih tinggi dibandingkan Megathyrsus maximus cv. Gatton.

Berdasarkan penelitian yang dilakukan oleh Hidosa et al. (2017) menyatakan bahwa produksi BK Chloris gayana 15,21 ton/ha/tahun dengan nilai berkisar 10 sampai 16 ton $\mathrm{BK} /$ ha dan dengan produksi terbaik 30 sampai 40 ton BK/ha yang dilakukan di Ethiopia, Tessema dan Feleke (2018) melaporkan bahwa produksinya mencapai 18 ton/ha/tahun sedangkan Rukmana (2009) pada penelitiannya, menyatakan bahwa hasil produksi segar Chloris gayana sebanyak 2,5 sampai 7,1 ton/ha. Berdasarkan literatur tersebut diketahui bahwa produksi BK Chloris gayana cv. Callide berada dalam kisaran normal demikian juga dengan BO, tetapi kadar BK masih lebih rendah, dimana Heuze et al. (2016), menyatakan bahwa kadar BK Chloris gayana yaitu 24,9\%, sedangkan BO Chloris gayana yaitu $89,6 \%$. Perbedaan nilai kadar bahan kering atau bahan organik sangat dipengaruhi oleh faktor lingkungan serta manajemen selama pemeliharaan.

Tabel 3 menyajikan data produksi segar Megathyrsus maximus cv. Gatton yaitu 121,02 ton/ha/tahun pada penanaman tahun pertama dengan 6 kali defoliasi, dengan permulaan tanam pada saat bulan Januari dengan curah hujan yang masih tinggi. Selama satu tahun diperoleh data produksi biomasa 32,44 ton BK/ha/ tahun, kadar BK 19,85\% dan kadar BO 88,18\%. Hasil analisis pada Tabel 2 menunjukkan bahwa produksi segar, produksi biomassa dan kadar BK pada Megathyrsus maximus cv. Gatton lebih tinggi $(\mathrm{P}<0,05)$ dibandingkan pada Chloris gayana cv. Callide. Perbedaan tersebut terjadi karena adanya perbedaan spesies karena dalam manajemen penanaman, lingkungan dan pemeliharaan semua dalam kondisi yang seragam. Penelitian Taute et al. (2002) di Afrika selatan melaporkan bahwa produksi 
BK dari Megathyrsus maximus cv. Gatton sebesar 0,75 sampai 2,5 ton/ha atau setara dengan 15 ton/ ha/tahun BK dengan 6 kali pemanenan . Hal ini menunjukkan bahwa Megathyrsus maximus cv. Gatton dapat berproduksi baik di Yogyakarta dan produksinya lebih tinggi.

Produksi biomasa bahan kering suatu hijauan pakan dipengaruhi oleh jenis spesies tanaman, kondisi atau fisiologis, kondisi kesuburan tanah, kadar air tanah, saat defoliasi atau umur tanaman, organ tanaman, kondisi lingkungan juga dipengaruhi oleh radiasi matahari dan suhu (Susetyo et al., 1969).

\section{SIMPULAN}

Berdasarkan hasil penelitian dapat disimpulkan bahwa Chloris gayana cv. Callide dan Megathyrsus maximus cv. Gatton dapat tumbuh subur. Hal ini karena kondisi lingkungan di Yogyakarta cukup mendukung pertumbuhan bagi kedua tanaman tersebut dan kemampuan tumbuh kedua tanaman yang baik. Produksi biomassa Megathyrsus maximus cv. Gatton saat ditanam di Yogyakarta lebih tinggi daripada Chloris gayana cv. Callide.

\section{DAFTAR PUSTAKA}

Astuti, M. 2007. Pengantar Ilmu Statistik untuk Peternakan dan Kesehatan Hewan. Cetakan Pertama. Binasti Publisher. Bogor.

Cook, B. G., B. C. Pengelly, S. D. Brown, J. L. Donnelly, D. A. Eagles, M. A. Franco, J. Hanson, B. F. Mullen, I. J. Partridge, M. Peters, dan R. SchultzeKraft. 2005. Tropical Forages. CSIRO, DPI\&F (Qld).

Corleto A., E. Cazzato, P. Ventricelli, S. L. Cosentino, F. Gresta, G. Testa, M. Maiorana, F. Fornaro, dan D. De Giorgio. 2009. Performance of perennial tropical grasses in different Mediterranean environments in southern Italy. Tropical Grasslands 43: 129-138

Fanindi, A. dan E. Sutedi. 2014. Karakter morfologi rumput benggala (Panicum maximum cv. Gatton) yang ditanam menggunakan jenis benih berbeda. JITV 19(1) : $1-8$.

Heuze, V., G. Tran, A. Boudon, dan F. Lebas. 2016. Rhodes grass (Chloris gayana). Feedipedia, a programme by INRA, CIRAD, AFZ and FAO. https://www.feedipedia.org/node/480 Last updated on April 15, 2016, 14:23

Hidosa, D., W. Hitiso, dan M. Guyo. 2017. Biomass production of different grass species available at irrigated lowland of Dassench Woreda in South Western Ethiopia. Bangladesh Animal Husbandry Association. Scientific. 46 (3): 188-191.
Landon, J. R. 1984. Booker Tropical Soil Manual. Longman Sci Tech. Essex England.

Murphy, S. 2010. Tropical perennial grasses - root depths, growth and water use efficiency. NSW Industry and Investment, Prime facts $\mathrm{N}^{\circ} 1027$.

Pieterse, P. A., N. F. G. Rethman, dan J. V. Bosch. 1997. Production, water use efficiency and quality of four cultivars of Panicum maximus at different levels of nitrogen fertilization. Tropical Grassland 31: $117-123$.

Prawiradiputra, B. R., Sajimin, N. D. Purwantari, dan I. Herdiawan. 2006. Hijauan Pakan Ternak di Indonesia. Badan Litbang Pertanian, Departemen Pertanian.

Rukmana, H. R. 2009. Rumput unggul sebagai hijauan makanan ternak. Buku 5. Penerbit Kanisus (IKAPI). Tersedia pada: https://www. kanisiusmedia.com. Diakses tanggal 12 Desember 2018.

Rusdiana, Supardi. dan I. Herdiawan. 2017. Pengetahuan peternak dan analisis ekonomi penggunaan rumput Chloris gayana sebagai pakan kerbau di lahan penggembalaan. Balai penelitian Ternak Ciawi, Bogor. Buletin Peternakan Vol. 41 (2): 219-229

Sajimin, E. Sutedi, N. D. Purwanti, dan B.R. Prawiradiputra. 2005. Agronomi Rumput Benggala (Panicum maximum Jac) dan Pemanfaatannya sebagai Rumput Potong. Pros. Lokakarya Nasional Tanaman Pakan Ternak. Puslitbang Peternakan. Bogor. pp 121-129.

Skerman, P. J. dan F. Riveros. 1990. Tropical Grasses. Food and Agriculture Organization of The United Nation.

Sutedi, E., R. P. Bambang, S. Armiadi, Sajimin, dan A. Fanindi. 2004. Karakterisasi rumput Rhodes (Chloris gayana) sebagai pakan ternak. Seminar Nasional Teknologi Peternakan dan Veteriner 2004. pp 842-845.

Syekhfani. 2001. Kesuburan Tanah. Penerbit Putra Media Nusantara. ITS. Surabaya.

Taute, A., W. A. V. Niekerk, N. F. G. Rethman, dan R. J. Coertze. 2002. An evaluation of nitrogen fertilised Panicum maximum cv. Gatton at different stages of maturity during autumn: 1 . Dry matter yield and certain qualitative parameters. South African Journal of Animal Science. 32(3): 208 - 215.

Tessema, Z. K. dan B. S. Feleke. 2018. Yield, yield dynamics and nutritional quality of grass-legume mixed pasture. The Journal of Animal \& Plant Sciences, 28(1). pp 155-164. 